\title{
Por que aprender História?
}

\section{Why learn History?}

\author{
Peter Lee ${ }^{1}$ \\ Tradução: Maria Auxiliadora Moreira dos Santos Schmidt e Marcelo Fronza ${ }^{2}$
}

\begin{abstract}
RESUMO
A partir da constatação de que ninguém escapa do passado e da importância da relação que as pessoas estabelecem com o passado, buscou-se apontar, a partir de pesquisa em fontes relacionadas à filosofia da História, alguns fundamentos para o significado da aprendizagem da história. Nesse sentido, temas como a importância da História para a validação do passado, a relevância das evidências, a problemática das leis e generalizações, bem como o significado da experiência vicária para a construção da aprendizagem histórica, foram objetos de análise, no sentido de se mostrar por que é importante aprender História.
\end{abstract}

Palavras-chave: aprendizagem Histórica; Educação Histórica; epistemologia da aprendizagem Histórica.

\begin{abstract}
Knowing that nobody escapes from the past and the importance of the relationship that people establish with the past, this aimed to point out some fundaments for the meaning of History learning, based in researches related to History's philosophy. Thus, themes such as the importance of History to validate the past, the relevance of evidences, the problematic of laws and generalizations and also the meaning of vicarial experience to build the learning of History were objects of analysis with the objective of showing why it is important to learn History.
\end{abstract}

Keywords: History learning; Historical Education; epistemology of History learning.

${ }^{1}$ Professor da History Education Unit - School of Arts and Humanities, University of London Institute of Education-UK.

${ }^{2}$ Maria Auxiliadora Schmidt é professora de Metodologia e Prática de Ensino de História e do Programa de Pós-Graduação em Educação da Universidade Federal do Paraná (PPGE/UFPR); é Coordenadora do Laboratório de Pesquisa em Educação Histórica da Universidade Federal do Paraná (LAPEDUH/UFPR). Marcelo Fronza é doutorando do PPGE/UFPR, professor da Rede Estadual do Paraná e pesquisador do LAPEDUH/UFPR. 


\section{O passado, historicidade e História}

Não se escapa do passado. Ele é construído a partir de conceitos que nós empregamos para lidar com o dia a dia do mundo físico e social. Algumas vezes os conceitos encapsulam o passado sob a forma de processos causais (ex. "árvore", "mãe", "bombas"). Algumas vezes, é envolvido um passado institucional - no caso de se falar em um governo ou uma criança ilegal, ou em casos que alguns critérios de legitimidade não foram encontrados. Mas, o controle do passado é sempre menos formal. "Ciência", "Comunismo" ou "Estado-nação" podem ser definidos de uma maneira mais ou menos informal pelos dicionários. Mas comunismo não é apenas o nome de símbolos de crenças ou atitudes, que nós podemos encontrar numa definição do dicionário ou mesmo numa análise escolar destas crenças ou atitudes. Parte do comunismo deve ser procurada no que os comunistas fizeram. E também para liberalismo, capitalismo e outros. Da mesma maneira, nossa noção de ciência importa a concepção de como determinadas formas ou atividades têm dado conta cientificamente do passado e um quadro de mudanças que a ciência tem causado na vida cotidiana. Da mesma forma, a noção que nós obtemos de estados-nações é inevitavelmente influenciada pela nossa compreensão do passado. O passado dá concreticidade aos nossos conceitos. Em muitas áreas do conhecimento, o passado é a referência para o nosso conhecimento de regras e para a nossa capacidade de selecionar acontecimentos. Alternativamente, o passado será o árbitro quando se precisa determinar se a aplicação de uma regra pode ser satisfatória ou não.

Os conceitos carregam uma bagagem temporal. Mas nosso mundo não consiste somente em exemplos de conceitos. Ele é povoado também por coisas individuais e particulares, com passados particulares. O Mercado Comum, Alemanha ou Guerra Fria de diferentes maneiras derivam muito das substâncias de suas extensões temporais. O Mercado Comum, por exemplo, é uma instituição que fez aumentar os preços na Grã-Bretanha e instalou um controle burocrático sobre a vida cotidiana das pessoas. É o passado que revela a natureza da instituição e, certamente, uma instituição dificilmente poderá ser considerada como algo espontâneo. Falar em renascer de uma instituição somente será inteligível como uma invocação do passado. Da mesma maneira, Alemanha é menos uma entidade geográfica do que uma entidade temporal e o que quer que o seu passado revele, ela será3. A Guerra Fria é o nome de uma "série de eventos particulares" e também de certa espécie de comportamento por parte

${ }^{3}$ Como usualmente Kitson Clark insere no coração do tema: "As palavras Alemão, católico e Judeu dizem respeito respectivamente a uma nação, a uma Igreja e a uma raça. Elas são usadas para descrever coisas as quais existem no mundo hoje e, assim, as reações dos homens a elas serão presumi- 
de pessoas, governos e estados. A vida útil desse conceito é incerta: recentemente pensou-se que ele morreu, mas os jornais, de tempos em tempos, predizem ou anunciam seu revival. Falar na ressurreição destes conceitos parece inteligível somente como uma invocação do passado.

Conexões entre o presente e o passado são mais do que isto. Ações são realizadas por algumas razões e pessoas (individualmente, em grupos sociais ou instituições) têm objetivos, procurando ou se colocando em determinadas situações. Estas situações, por sua vez, são frequentemente compreendidas quando referidas em termos de passado. Um agente (ou instituição) vê a si mesmo como estando ameaçado, ou insultado, ou enfraquecido; uma série de eventos é caracterizada em termos de tradições, as quais prescrevem não somente como tais eventos poderiam ser vistos, mas a partir de que exemplos um conjunto de respostas pode ser dado (entre a diplomacia ocidental, o trade unionismo, a política e as finanças do capitalismo, por exemplo, nós podemos encontrar eventos caracterizados como apaziguamentos, lockout, democratização ou crescimento industrial). As razões para as ações são referenciadas no passado e precisam ser entendidas pelas suas próprias razões. Em geral, como Olafson tem apontado: "Nosso sistema de distinções temporais é colocado à nossa disposição por seres que estão, eles próprios, no tempo, e [...] sendo este o caso, eles devem ser pelo menos uma característica de suas situações do presente e não podem ser descritos sem referência a uma situação precedente". (OLAFSON, 1979, p. 97; p.150).

"Historicidade", ou abrindo o passado e o futuro, é central para a compreensão do que é aprender história. Mas historicidade é uma coisa, e história

damente condicionadas pelo que elas são agora. De fato, contudo, em cada caso, as reações humanas são largamente afetadas pelas memórias da história, ou o que é tomado como história, o que parece desconectar a natureza de Alemães ou Judeus, ou Romanos Católicos, de suas ações. (KITSON CLARK, G. The Critical Historian. Portsmouth: Heinemann Educational Books, 1967, p. 6). Dois comentários podem ser feitos a isto. Primeiro, exemplos menos dramáticos são igualmente significantes. Segundo, para Kitson Clark é medianamente surpreso o fato de as pessoas hoje não considerarem as coisas como elas realmente são, e isto seja talvez injustificável. Diante deste ponto de vista, até agora, nós podemos falar das "grandes entidades históricas" (ou pelo menos então para este assunto), não há uma série de momentos presentes desconectados, mas entidades temporais, as quais carregam seus passados com elas, como habitantes, crenças, papéis, filosofias de vida, constituindo relações sociais. Mesmo onde há uma "maior ruptura" com o passado (por exemplo, Alemanha em 1945, onde instituições, moralidade pública e filosofia política sofreram mudanças repentinas), o passado é ainda inescapável; devido a questões ainda suspensas como quão profunda esta ruptura se fez, e em virtude de o que é uma ruptura, "O que a Alemanha é agora" não poderia ser respondido sem uma referência ao passado, mesmo que todos os alemães sejam questionados pelos sociólogos e cientistas políticos, porque o passado estaria embebido nas respostas. "O passado, o presente e o futuro formam um simples domínio de referência [...] entre o qual o presente tem somente um tipo de prioridade qualificada [...]" In: Heidegger's parlance, a human life "stretches itself along". (OLAFSON, F.A. The dialectic of Action. Chicago: University of Chicago Press, 1979. p. 97). 
outra. Falar que os seres humanos são no tempo e estas ações referem-se a eventos do passado, ou que particularidades como "Alemanha" ou o "Mercado Comum" carregam com elas concepções dos seus passados, não é dizer que tipo de passado está em questão. Portanto, a Guerra Fria pode ser o nome de um grupo coligado de eventos e ações historicamente reconstruídos, ou pode ser o nome de uma explanação política, social ou de um mito nacionalista. Nós não podemos escapar de um tipo de passado. Mas nós podemos estar em condições de escolher que tipo de passado nós teremos. J. H. Plumb (1969, p.17) nos oferece a escolha entre um mero passado, o qual é "sempre uma criação ideológica com um propósito, designado para controlar indivíduos ou motivar sociedades, ou inspirar classes", e história, cujo futuro é "limpar a "história" que é feita com o objetivo de formar visões propositais sobre o passado. Onde o passado é usado para legitimar autoridades ou oferecer um guia para o destino, história "por sua própria natureza [...] dissolve-se simplesmente, por meio de generalizações estruturais a partir das quais nossos antepassados interpretaram, historicamente, as finalidades da vida." $(1969$, p.136). Além disso, Plumb conclui que a morte do passado já nos precedeu: "História, a qual é profundamente comprometida com o passado, tem, num sentido, ajudado a destruí-lo como uma força social, como uma sintética e compreensiva declaração do destino da humanidade.”(1969, p.14)4. Para Plumb, a História é destrutiva, mas pode "ainda ensinar sabedoria". Ela oferece um passado no qual o fazer das condições humanas melhorou por meio do uso da razão. O que não fica claro é se esta sabedoria é substantiva ou formal. Por enquanto, a grande contribuição que o historiador pode fazer é ensinar para todos, literalmente, a natureza da mudança social, e, "naturalmente, não haverá acordo entre historiadores que falam com as suas diferentes vozes (1969, p. 142-143). Há, então, na perspectiva de Plumb (1969, p. 144), uma ambiguidade entre história como, de um lado, um instrumento formal e negativo e, de outro lado, como uma fonte de sabedoria positiva, fornecendo os conhecimentos dos "mecanismos das mudanças históricas", demonstrando o papel da razão nos sucessos humanos e, portanto, preenchendo, pelo menos, alguns dos significados do passado morto.

Uma outra questão que pode ser levantada a partir da posição de Plumb é se o seu obituário da morte do passado não é prematuro. É o passado realmente morto ou ele está morrendo? É verdade que a história destrói os passados particulares "como um cupim trabalhando no coração da madeira - sempre ativo, mas raramente visto na superfície.” (1969, p. 123). Mas a destruição do

${ }^{4}$ Mas Plumb não dá somente à história o crédito para isto. Veja a página 14 da mesma obra. 
passado particular não significa, necessariamente, o fim do passado. Escrevendo dois anos antes de Plumb, Kitson Clark foi menos sanguinário. Ele advertiu sobre a desordem massificada dos conhecimentos nebulosos, das informações fragmentadas, das ficções e vestimentas fantasiosas e nem sempre conscientes memórias históricas [...] entrelaçados num grupo de associações históricas as quais se esparramam acima da consciência humana inteira. Portanto, palavras são convertidas em pragas, símbolos são dotados com força emocional e estereótipos emergem, os quais pretendem descrever grupos inteiros de pessoas e predizer, a partir dos seus passados, suas condutas possíveis no futuro (KITSON CLARK, 1967, p. 7) .

Não há razão aparente por que um passado deste tipo não tenha pretensões de fornecer as sanções e as chaves para o destino o qual Plumb acreditava estar desacreditado pela história. A História então não tem efeito? É o passado um monstro de sete cabeças? É tentador perguntar que, se a história não pode extirpar o passado, ela tem o prolongado indefinidamente, dotando-o com um grupo de um longo processo evolucionário e transformando-o dentro de uma mudança mais ou menos rápida.

A maioria dos homens e mulheres [...] acreditam que eles são parte de um processo histórico que vem mudando através dos séculos [...] e que o processo de mudança tem acelerado e está acelerando, então é necessário saber o que a natureza deste processo tem sido e é. Eles necessitam de um passado histórico, objetivo e verdadeiro (PLUMB, 1969, p 16).

Não há dúvida que a história tem uma mão nisto: mas aqui parece ser uma pequena dúvida, que a ciência natural e as mudanças sociais causadas pelo rápido desenvolvimento industrial e urbano possuem, pelo menos, um papel igual ${ }^{6}$. Não menos do que isto, por alguma razão, nós trazemos até nós um passado bastante longo, complexo e confuso, além de dinâmico o bastante para reduzir o poder de alguma sanção particular ou destino que possam ser encontrados nele, e o passado apela à história para a sua validação. O passado ainda contém heróis e grandes homens, exemplos morais e míticas idades do ouro. "Eventos históricos" ainda rolam rapidamente das bocas dos comentadores e jornalistas. Mas a noção de evento histórico é importante: por todas as suas conexões e sensacionalismos e o Guinness Book of Records carrega com ele a

${ }^{5}$ Este autor acredita que a base do passado é "confusamente lembrada a partir de lições aprendidas na escola", "as reinterpretações de afirmações políticas", "as misteriosas coleções de controvérsias jornalísticas", "fragmentos de informações especiais de experiências pessoais" ou as histórias de chances coincidentes, e "a pintura clara de situações históricas ou de personagens conhecidos, pelas novelas históricas ou filmes".

${ }^{6}$ Veja Toulmin, S.; Goodfield, J. The discourse of Time. London: Hutchinson, 1965. 
ideia de escriba da história, escondida em suas asas, gravando, analisando e pesando o significado dos eventos. A princípio, o passado é agora o lugar da história e, a despeito da ambiguidade do que "a história mostra", é a história como disciplina racional que está reorganizada como corte de apelação, mesmo se estes procedimentos são pouco entendidos ${ }^{7}$.

Se a divisão de Plumb entre o passado e a história não é suficiente e seu epitáfio para a história é também apressado, a distinção de Michael Oakeshott entre história e "passado prático" pode ser pensada como também radical ${ }^{8}$. Nós descuidamos da história no passado prático, quando "o passado parece ser uma relação específica com o presente" ou é "designado para justificar [...] crenças práticas acerca do presente e do futuro" (OAKESHOTT, 1933, p. 105). Este é o passado usado pelo advogado, político ou sacerdote. Entretanto, no histórico, como oposição ao passado prático, não existem culminâncias, acontecimentos principais, pontos de referência ou catástrofes: somente um mundo de eventos inter-relacionados ${ }^{9}$. Em história, nenhum homem morre rapidamente por "acidente; $[\ldots]$ Nada está previamente aprovado, não existem condições previstas a partir das quais as ações podem se realizar e nada está denunciado (OAKESHOTT, 1962, p. 148). O passado prático "consiste em acontecimentos

${ }^{7} \mathrm{O}$ conceito de "A corte da história", no qual historiadores são alguma coisa como juízes e (nas palavras de Ambroise Bierce) grandes e meticulosos fofoqueiros, fazendo e desfazendo reputações, não declarando abertamente as noções de história e de passado. Fundamentalmente, isto pertence ao "passado prático", mas, em reconhecimento ao fato de que historiadores empregam evidências a partir de certos procedimentos mais ou menos acordados entre eles, admite-se que a história é uma disciplina racional na qual o passado é alguma coisa a ser investigada e que as conclusões dos historiadores são elas mesmas submetidas ao criticismo.

${ }^{8}$ Embora existam alguns problemas no The death of the past, ele é uma das poucas referências da história e seu desenvolvimento, o qual em geral sustenta a interpretação da historiografia Whig. Paradoxalmente, o livro Man and his Past, de Herbert Butterfield (Cambridge, UK: Cambridge University Press, 1969), está radicalmente infestado por tal interpretação, na qual a história da história parece como um tipo de força confusa para responder a problemas modernos, a qual poderia somente ser bem-sucedida se acompanhada pela moderna crítica metódica: outros interesses no passado tendem a ser deixados de lado como primitivos ou como tristes tentativas para a história. Uma aproximação semelhante está baseada no livro Annalists and Historian (London: Methuen, 1977), de Denys Hay. Plumb fez um ou dois comentários descaracterizados (por exemplo, seu comentário sobre a longevidade dos patriarcas, p. 122), mas em geral apresentou uma ampla visão, examinando diferentes conceitos do passado em seus próprios termos, tanto quanto incentivando o crescimento da crítica histórica. Naturalmente, há um sentido legítimo no qual o desenvolvimento do conceito racional de história precisa ser encontrado, e Collingwood forneceu em seu livro The Idea of History um esboço inacabado de como isto poderia ser feito. Mas, tal referência é a história de um trabalho progressivo fora dos grupos de referência e é tão filosófico quanto histórico. A história de nossa compreensão do passado está quase da mesma maneira na triste posição da história da ciência trinta anos atrás. A História da ciência foi além da catalogação linear da atual concepção do mundo natural e está começando a elucidar as origens históricas e racionais de outras concepções. A história do passado aguarda tratamento semelhante.

${ }^{9}$ Ver: DRAY, W. H. "Michael Oakeshott's theory of history". In: PAREKH, B. C.; KING, P. T. (Eds.). Politics and Experience. Cambridge: Cambridge University Press, 1968. p. 32. 
reorganizados para contribuírem às sucessivas condições das ações", enquanto que a história representa um interesse nos eventos do passado [...] respeitando sua independência nas sucessões do tempo ou nos eventos do presente (1962, p. 154/155). É necessário admitir que se a análise de Oakeshott impõe limites impossíveis à história e, ao mesmo tempo, a corta pela raiz - não há nada errado em princípio com pesquisas partindo de interesses correntes ou problemas práticos ${ }^{10}$. Mas a força desta referência é que ela nos permite distinguir entre um passado leigo habitado por heróis e observado em lições de moral e o passado histórico que é paralelo a ele, não enterrando prematuramente o passado leigo, já que agora teríamos um passado histórico para substituí-lo, mas reconhecendo diferentes caminhos pelos quais o passado continua a ser tratado ${ }^{11}$.

O limite que tanto Plumb e Oakeshott têm a dizer é que sem história não pode haver passado racional. Certamente, se na ausência da história o passado é apenas prático, é difícil ver como poderia haver uma concepção consensual sobre o passado, mesmo em princípio; mesmo se houvesse ocorrido na vida prática. (E se esta condição for encontrada, o mundo seria muito diferente daquilo que é correntemente) ${ }^{12}$. Sem história o passado serve meramente a interesses práticos e assim, em um importante sentido, nós seríamos destituídos de nossa própria experiência. Para a pesquisa histórica, é simplesmente uma investigação racional do passado e, desde que nós não podemos escapar do

${ }^{10}$ Os limites impossíveis aqui referidos são inerentes em largo sentido ao dado por Oakeshott para "prático" em sua justaposição ao passado histórico e prático. É difícil ver, por exemplo, por que o tratamento histórico dado ao Tratado de Versalhes deveria excluir conexões com "eventos subsequentes" na Alemanha e há necessidade de distinguir, à primeira vista, do tipo de tratamento que vê o Tratado como justificativa para a destruição da República de Weimar, ou examinar alguns aspectos dele como sendo a "origem" de alguma parte do presente. Para a discussão do ponto de vista histórico de Oakeshott, ver o artigo de Dray referenciado na nota 5 e também na antologia de Walsh, W. H. "The pratical and historical past".

${ }^{11}$ Não existe intenção aqui em sugerir a ideia do "passado tratado de diferentes maneiras" e que não existem questões sobre se o passado é descoberto ou constituído. Oakeshott em nenhum caso olha o passado como o presente sendo de uma maneira particular. Mas, não é o lugar de discutir este assunto.

${ }^{12}$ Teria que haver um mundo sem moral, religião ou disputas legais e sem disputas de interesses materiais. Talvez uma concepção pré-freudiana de sociedade socialista como entendida por Marx pode alcançar algum lugar próximo a ser encontrado? Mas, deixada deste jeito, minha referência é muito simples. Há limites para a objetividade histórica, mas ela pode ser a base de nossa avaliação para o que é relevante para uma pesquisa ou (mais amplamente) o que é importante em história, até agora como isto não foi estabelecido com antecedência pela pergunta feita, ou por qualquer sorte de teoria, está a ser encontrado em alguma forma compartilhada de vida. De acordo com a relativa importância das mudanças massivas no modo de vida possível para um vasto número de pessoas, de uma longa expectativa de vida e de liberdades de vários tipos, é talvez para ser guiada para algum acordo básico em aparatos psicológicos, percepções importantes ou outros. (Algum tipo de caso poderia não ter dúvidas de fazer na direção das linhas de Wittgenstein, mas estão de maneira ambígua no olhar de Wittgenstein sobre "formas de vida", os quais apresentam dificuldades). (Ver também nota 22). 
passado, nós temos que procurar o melhor conhecimento que pudermos obter sobre $e^{13}{ }^{13}$. É por esta razão que se torna original perguntar que uso a história tem ou por que a história poderia ser aprendida. Se nosso conhecimento do mundo presente não é nunca um "conhecimento instantâneo", e nos traz, quer queira, quer não, alguma concepção substantiva do passado, então, ser historicamente ignorante é, justamente, ser ignorante.

\section{Evidência}

Afirmei que a história fornece o único meio racional de investigar o passado. Esta afirmação se baseia em parte no conceito de desenvolvimento de evidência na história (e das técnicas de manuseio) da evidência. Tem havido uma grande discussão sobre evidências históricas e sua importância para o ensino de história nos últimos anos e eu não desejo discutir os pontos fortes e fracos dos métodos e dos conteúdos específicos de aulas aqui. O que é importante para o assunto em mãos é que, se o uso de evidências é o que, de certa maneira faz uma investigação racional do passado possível, então ser

${ }^{13}$ Tudo o que é dito neste capítulo planeja sugerir a justificativa de uma forma de conhecimento para a história e, com isto, uma ênfase na sua aquisição na escola sob a forma de uma disciplina. Resta a complexa questão de como a história substantiva deve ser ensinada; um assunto largamente comentado nos últimos quinze anos, invocando os critérios da pedagogia pelos quais tudo pode ser ensinado, os quais exemplificam a disciplina - algumas vezes as habilidades - da história. Isto não é suficiente: primeiro, porque entre os paradigmas dos períodos selecionados uma escolha deverá ser feita entre o que é importante e o que não é; e, segundo, porque o ensino de uma disciplina também envolve o ensino de seus critérios de importância. O que estes critérios são é uma questão a ser trabalhada. Não há espaço neste capítulo para fazer um esforço sério para esmiuçar isto, mas vale a pena arriscar um ou dois comentários. É impossível prover as crianças, com antecedência, dos seus interesses, com um catálogo de "tudo o que você precisa saber". Os interesses práticos, de alguma forma, não podem organizar o passado no ensino de história, ou o passado prático tomará o lugar da história. Mas, considerando que nós somos os tipos de pessoa que somos, vivendo a vida que nós vivemos, nós somos propensos a ter interesse mais em uma passagem do passado do que em outra. Já foi colocado que, como seres humanos, nós compartilhamos uma forma comum de vida e em algum nível isto nos permite a possibilidade de uma intersubjetividade consensual do que é humanamente importante. Isto feito, talvez (minimamente) um passo pode ser ganho sobre o conceito do que é intrinsecamente importante em história. Isto também pode ser um argumento acerca da própria natureza da história. A atividade histórica pressupõe, pelo menos, a preocupação quanto à liberdade em assegurar o que a evidência nos leva a crer (para nós mesmos e para os outros); e também uma concepção de homem como um ser racional (como oposto a irracional). Isto pressupõe uma igualdade de tratamento e um respeito por pessoas como fontes de argumentos. Nestas circunstâncias, isto parece ser profundamente razoável sem poderosos contra-argumentos (e o ônus disto recai em quem desagrada a produção destes argumentos) para negar que estas mudanças do passado estão no curso da liberdade, igualmente no respeito pelas pessoas e no desenvolvimento da racionalidade da sociedade, como de importância intrínseca para a história. Inquestionavelmente, tudo isto envolve apelar para alguma concepção de interesse humano e talvez também para um critério implícito de educação; mas o histórico e o educacional não estão em conflito aqui. Mesmo os historiadores mais limitados necessitam alguma ideia de diversidade da vida humana e do que é possível para o homem ser e fazer. A importância do histórico depende de uma concepção de interesse humano e a história nos possibilita usar esta concepção criticamente. 
capaz de usar evidências é, dessa forma, aquisição valiosa. Mas, há limites quanto ao que pode ser afirmado aqui. Não se pode presumir que o conceito de evidência histórica é coextensivo com o conceito de evidências em geral e a maneira pela qual a evidência é usada na história não é necessariamente a mesma como ela é usada em, digamos, ciência natural. A diferença é, em parte, relacionada às técnicas, mas existem diferenças mais fundamentais. As perguntas a serem respondidas são diferentes e, em consequência e também em grande parte, o material evidencial. Eu não posso aprofundar este ponto corretamente aqui, mas é óbvio que as questões como o que se pretendia, em certas ações, não surgem em conexão com o comportamento de objetos inanimados e o significado de um documento ou o significado de uma prática social ou daqueles que dela participam não tem qualquer contrapartida com os problemas evidenciais na ciência natural.

Pode parecer que o preço a ser pago para distinguir a evidência na história da evidência em outras disciplinas empíricas é alto: aprender a lidar com a evidência histórica pode não ter nenhum valor de transferência para outras disciplinas. Se a aprendizagem da história é importante, também o será aprender a usar a evidência histórica, mas o último não pode dar apoio independente ao primeiro, uma vez que dele deriva. Mas isso não é tão restritivo quanto parece e certamente não limita o que é aprendido no uso de evidência histórica do passado obscuro e morto. Já vimos que o passado não pode ser claramente dividido a partir do presente: a compreensão de uma pessoa não pode ser isolada da compreensão da outra. É verdade que ensinar as crianças a usar a evidência histórica não pode ser, ipso facto, equipá-las para fazer uso efetivo do passado prático; talvez as pessoas empreguem mais facilmente o passado para resolverem os seus problemas atuais, quando estão cientes apenas do passado prático. Alguém pode até ter argumentado que as crianças precisam de respostas rápidas para problemas práticos e não da história, que trará para elas apenas paralisantes dúvidas acadêmicas. Mas seria difícil ter uma visão tão séria como a da educação prescritiva, porque equivaleria a uma negação da importância da verdade e, com ela, de toda a atividade cognitiva. (Talvez as doutrinas mais próximas de tal posição nos tempos modernos sejam o futurismo e o fascismo.) Menos geralmente ela equivaleria a uma bênção sobre os usos do passado deplorado por Plumb e tão claramente exemplificado na contemporânea Irlanda do Norte.

Aprender a usar a evidência histórica e talvez, acima de tudo, adquirir a "paixão racional" - concernente à verdade, objetividade e assim por diante, que são essenciais para a operação dos procedimentos históricos - é tanto uma das principais razões para a aprendizagem da história como uma parte central do que a aprendizagem histórica realmente implica. 


\section{Leis, lições e generalizações}

A relação entre o passado e o presente envolve outros aspectos da história. Entre os historiadores acadêmicos, talvez uma das justificativas mais desacreditadas para a história é que ela ensina "lições". Políticos, jornalistas e muitos outros (incluindo alguns historiadores profissionais) ainda assim persistem em pensar que a história tem lições a ensinar. Munique, a experiência do conflito racial nos EUA e a Revolução Industrial são colocados diante de nós como exemplos do que pode, poderia ou vai acontecer se (respectivamente) os poderes da Otan tivessem tentado "apaziguar" a antiga URSS. A decadência urbana interior e a discriminação racial continuam desenfreadas, ou o chip de silício não é aproveitado de forma adequada. Inquestionavelmente, o passado pode ser pressionado em favor de uma causa, na defesa de um curso de ação, pelo menos como um passado prático. Mas há algo como isto que, legitimamente, pode ser procurado no passado histórico?

As "lições da história" são geralmente enquadradas como generalizações de algum tipo, apoiando as previsões. Estas últimas podem ser advertências de como o mundo vai "agir" como se fosse por si só, se um determinado curso de ação não for orientado. Alternativamente, podem se declarar e demonstrar as possíveis (mesmo "inevitáveis") consequências de uma ação particular, enfatizando a sua conveniência ou inconveniência. Na ciência natural, é claro, as previsões são frequentemente baseadas em teorias que incorporam as declarações de regularidades ou leis gerais e especificação das condições iniciais relevantes. E a aplicação da ciência a problemas práticos resultou em sucessos surpreendentes. É tentador pensar que, portanto, as generalizações que são ou formam a base das "lições" da história são equivalentes às teorias formalmente articuladas do paradigma científico, apenas talvez um pouco menos precisas. Tal suposição é perigosa. Este não é o lugar para tentar uma análise aprofundada da possibilidade ou da função lógica de leis gerais da história, mas alguns comentários não podem ser evitados ${ }^{14}$. Há claramente generalizações somativas na história que são explicativas do ponto de vista do senso comum, mas fornecem

\footnotetext{
${ }^{14}$ A discussão sobre "leis" e "generalizações" em história é frequentemente feita com dificuldade para distinguir as diferenças dos tipos envolvidos. Uma lista simplificada poderia ser essa:

(a) generalizações reduzindo a um número finito de casos conhecidos;

(b) generalizações sobre um individuo,

(c) leis universais, se "confirmado" ou meramente "provado", isto é - "verdade plausível", a qual envolve diferentes sentidos de probabilidade a partir da qual segue o item (d);

(d) leis estatísticas, apresentando probabilidades numéricas - isto é, eventos de um certo tipo ocorrendo em uma população de eventos de outro tipo;

(e) leis normativas, descrevendo as tendências das coisas (ver BHASKAR, R. A realistic theory of science. London: Version, 1997);
} 
uma base frágil para a predição. Como Atkinson salienta: "A surpresa de alguém [...] que uma determinada Reforma do Parlamento foi preparada é, inegavelmente, diminuída pela descoberta de que todas elas foram." (ATKINSON, 1978, p. 111). Mas, a menos que saibamos por que elas estavam preparadas, não podemos empregar a generalização de alguma forma útil, para além dos casos que foram resumidos ${ }^{15}$. Então, algo mais é necessário: talvez, leis universais ou generalizações estatísticas?

Sem dúvida, em princípio é possível que as leis universais ou generalizações estatísticas possam ser descobertas como aplicáveis à história. Também pode ser que, ao dar explicações, historiadores necessariamente comprometam-se com a afirmação implícita de que alguma lei que cobre uma explicação existe, mesmo que ninguém possa formulá- $\mathrm{la}^{16}$. Mas, mesmo se ambos os argumentos forem aceitos (e não é sem dificuldades) ofereceriam pouca orientação sobre as questões centrais a este capítulo. Em primeiro lugar, leis universais e genuinas aplicáveis à história possivelmente são de baixa probabilidade, no sentido de que as chances delas serem verdadeiras são pequenas. É difícil pensar em um único exemplo em que isto não se aplica. Em segundo lugar, as leis estatísticas, que podem ter uma melhor pretensão de verdade, são aplicáveis a uma gama limitada de áreas, onde há um grande número de eventos que podem ser considerados como "os mesmos"; normalmente eles são encontrados na história demográfica (e alguns na história econômica). Olafson argumentou que "as múltiplas rotinas pelas quais a vida de uma comunidade humana é organizada e estabilizada" - arando um campo, por exemplo - são do tipo "recomeçou de novo e de novo sem mudança significativa", e toda a história delas seria "uma releitura de uma história que já foi contada inúmeras vezes". Colocadas lado a lado, essas "histórias" [seriam] essencialmente autossuficientes e [poderiam] ser entendidas sem referência a qualquer episódio em especial (OLAFSON, 1979, p.115-117). ${ }^{17}$. Para que uma história seja possível, os eventos devem ser "logicamente cumulativos". Pessoas descrevem eventos de modo a escolher (a partir das muitas descrições possíveis disponíveis) certas características a que elas poderão reagir. Estas características refletem as crenças, expectativas, intenções e propósitos de quem está reagindo,

(f) truísmo (ver SCRIVEN, M. "Truisms as the ground for historical explanation". In: GARDINER, P. (Ed.). Theories of History. Free Press, 1959.

(g) "Leis" heurísticas ou generalizações;

(h) Principios de ação. Considerando a preocupação desse capítulo, a discussão irá ser focada nos itens (a), (c) e (d), mas também será feita breve referência em relação aos itens (g) e (h).

${ }^{15}$ Exceto enquanto um instrumento heurístico.

${ }^{16}$ Ver WHITE, M. Foundation of historical knowledge. Harper \& Row, s/d., p. 14-104.

${ }^{17}$ Ver também p. 100-101. 
os quais pressupõem uma capacidade para referir-se a pontos anteriores ou posteriores, na ordem do tempo [...] para se referir.

Dentro de um contexto desse tipo, o evento original assume um significado - como uma ameaça, por exemplo, ou como a criação de uma oportunidade, que lhe dá uma orientação no tempo, como bloquear ou facilitar outras ações possíveis. Assim, um evento inicia uma sequência em que reações apropriadas são feitas para eventos passados vistos da mesma maneira (OLAFSON, 1979, p. $100-101)^{18}$. As rotinas recorrentes, que são típicas do domínio de leis estatísticas (sobre, por exemplo, o número de nascimentos por mil, sob certas condições) não exibem esse caráter "logicamente cumulativo". Assim, tais leis estatísticas, como são atualmente encontradas na história, estão confinadas a certos tipos específicos de análise histórica. Claro que, a longo prazo, rotinas recorrentes podem produzir alterações (por exemplo, a erosão do solo ou uma explosão populacional) que exigem uma ação fora do repertório estabelecido de tais rotinas: mas é precisamente este tipo de alterações que fazem com que o estabelecimento de leis estatísticas dificilmente transcenda determinadas épocas e lugares. O ponto deste capítulo não é que não existe nenhum candidato para o status de tais leis, ou que tais leis nunca são pressupostas nas explicações históricas, mas que poucos poderiam apoiar previsões. E se é difícil pensar em qualquer lei estatística, seria de arriscar a própria camisa que é ainda mais difícil de encontrar qualquer lei universal bem fundamentada.

Há uma razão importante para isso. Assim como não há leis da física sobre radiadores de automóveis quebrados que vão explicar por que um radiador especial quebrou, mas sim leis de mudanças relativas à pressão de líquidos conforme a temperatura e volume, então na história não é de se esperar que haverá leis sobre a derrubada dos reis ou sobre as ações dos secretários estrangeiros. Mas, na história, ao contrário da física, não há ainda nenhum conjunto de conceitos abstratos do tipo certo. Mesmo que tais esquemas conceituais fossem desenvolvidos, haveria problemas importantes sobre seu emprego na história. Isso acontece porque muitos eventos históricos são referências para trás e (no sentido de Olafson) "logicamente cumulativos". A estrutura conceitual nos termos pelos quais esses eventos são escolhidos e compreendidos pelos agentes envolvidos é a prática cotidiana, na qual as coisas são feitas por razões. O significado disso é trazido pela consideração de alguns pontos que foram levantados por Davidson ${ }^{19}$. Afirmações causais, argumenta Davidson, implicam

${ }^{18}$ Conferir a discussão de G. H. von Wright sobre "as cadeias quase causais". In: Explanation and Understanding. London: Routledge \& Kegan Paul, 1971, p. 139-143.

${ }^{19} \mathrm{Não}$ há espaço aqui para discutir a possibilidade da sociologia histórica que investiga estruturas de mudanças na sociedade. Os marxistas às vezes argumentam por algo mais fechado do que isso, 
leis apenas no sentido fraco que "A causou B" e "implicam que existe uma lei causal explicada por algumas descrições verdadeiras de A e B". Podemos dar explicações causais válidas, sem conhecer leis preditivas pertinentes. Além disso,

[...] uma generalização, como "Janelas são frágeis, e as coisas frágeis tendem a quebrar quando atingidas forte o suficiente, nas mesmas condições" não é uma lei preditiva em bruto - as leis preditivas, se elas existirem, seriam quantitativas e usariam diferentes conceitos. A generalização, como a nossa generalização sobre o comportamento, tem diferentes funções: ela fornece evidências para a existência de uma lei causal, cobrindo o caso à mão (DAVIDSON, 1968, p. 91-92).

Por conta disso, a história pode ser explicativa sem ser preditiva. No caso do comportamento humano, isto é particularmente importante. Se quisermos explicar uma ação (caracterizada em termos do dia a dia), não precisamos de (e não podemos ter) uma lei no sentido de que pessoas acreditam de tal ou qual forma ou possuem tal maneira de agir. Para ter certeza, a ação irá instanciar (sob alguma descrição verdadeira) leis causais - então, razões são "causas racionais". Mas essas leis causais não lidam com conceitos em que a explicação racional tem de lidar (onde noções como evidência, boas razões para acreditar, e assim por diante, devem entrar). Os conceitos necessários nas leis causais relevantes e, se nós os soubéssemos, "podem até ser de química, neurologia ou física" (DAVIDSON, 1968, p. 93) ${ }^{20}$. Leis empregando esse tipo de estrutura

e os conceitos marxistas têm afirmações preconcebidas em relação ao nível necessário de abstração. Mas, o tipo de estudo examinado por marxistas não empregaria leis da mesma forma (dito) por Hempel. Ver Bhaskar, op. cit. e sua The possibility of naturalism, Harvester, 1979; também, Cohen, G. A. Karl Marx's Theory of History, a defense. Oxford: Oxford University Press, 1979.

${ }^{20} \mathrm{O}$ argumento de Davidson pode ser (cruamente) resumido como: (a) Se desejo e crença são para explicar uma ação do modo certo, eles devem provocá-la do mesmo modo: talvez através de uma corrente de raciocínios, encontrando modelos de racionalidade; (b) nós não podemos distinguir o tipo certo de processos causais sem levar em conta como a decisão é alcançada à luz do conflito de evidências e do conflito de desejos; isso significa que nós devemos usar as noções de evidência, boas razões para acreditar, entre outras. Portanto, (c) nós não podemos fornecer condições suficientes e necessárias para agir sobre a razão, se nós usamos somente conceitos como crença, desejo e causa. (d) Pelas mesmas razões, nós não podemos fornecer leis sérias, conectando razões e ações. Se nós tivéssemos condições suficientes poderíamos dizer: "Toda vez que um homem tem tais e tais crenças e desejos, e tais e tais condições satisfeitas, nós agiremos de tal e tal modo". Não existem leis sérias como essa (i.e. com probabilidades fixas, transbordando a partir da natureza da teoria, e onde ela é possível para determinar, posteriormente, se as condições de aplicação são satisfeitas). In "Psychology as philosophy" (In: GLOVER, J. (Ed.). The Philosophy of mind. Oxford: Oxford University Press, 1976) Davidson conclui que atitudes, crenças, desejos etc. "não são, mesmo na teoria, disponíveis para predição precisa ou subsunções sobre determinadas leis. O limite, então, colocado sobre as ciências sociais, é posto não pela natureza, mas por nós, quando decidimos ver o homem como um agente racional, com objetivos e propósitos, e como sujeito capaz de avaliar moralmente”. (p. 109-110). 
conceitual não poderiam lidar com eventos entendidos como razões de qualquer modo, muito menos sob a forma de descrições, tão frequentes na história, em que razões são as "referências passadas". Um quadro conceitual que ultrapassasse razões, ultrapassaria essas razões também, e seria, portanto, incapaz de explicar um relacionamento central entre passado e presente. Se Olafson está certo, isso tornaria grande parte da história impossível.

Naturalmente, há muito mais neste argumento ${ }^{21}$. O que importa para este capítulo, no entanto, é que, mesmo na análise mais plausível de razões como causas, ainda há sérias dificuldades para qualquer afirmação que podemos esperar para conseguir leis universais, influenciando sobre a ação humana interpretada como ação. Temos na história poucas (se houver) leis universais que poderiam suportar o peso de predições. Nós talvez poderemos (no futuro) ter tais leis, ao preço de um novo quadro abstrato conceitual. O preço a ser pago seria que seremos incapazes de explicar as razões como razões e ações como ações.

Se o estudo da história não oferece leis nas quais as previsões podem ser baseadas, pode oferecer tudo o que nos dará algum produto no futuro? A primeira coisa a notar é que, no senso comum e na ciência prudente, previsões condicionais são possíveis sem leis (algo reconhecido de uma forma qualificada pelo próprio Hempel) $)^{22}$. Uma vez aceito que é possível dar apoio indutivo para afirmações sobre o futuro, independente de leis gerais, a previsão com base no conhecimento histórico já não é, em princípio, inadmissíve ${ }^{23}$. Enquanto se reconhece que todas as previsões são condicionais (particularmente na história, onde as coisas muitas vezes se recusam a permanecerem iguais, mas em vez disto mudam) e que não é objetivo da história servir de base para a previsão (história - até mesmo a história marxista - não é organizada dessa forma), não há mal em dizer que o conhecimento histórico pode, por vezes, permitir que as previsões sejam feitas ${ }^{24}$. Em segundo lugar (sem invocar leis gerais), explicações sempre têm implicações para além do caso em mãos. Se alguém cita A como uma explicação de B, pode-se repudiar uma explicação semelhante em outro caso somente se houver uma diferença relevante entre eles. Isso não justifica tanto a

\footnotetext{
${ }^{21}$ Para um argumento mais detalhado, ver Peare, D. Questions in the philosophy of mind. Duckworth, 1975, especialmente o capítulo 5; "Sketch for a causal theory of wanting and doing"; Mackie, J. L. The cement of the universe. Oxford: Oxford University Press, 1974, cap. 11: "Teleology"; Davidson, D. "Psysichology as Philosophy". In: Glover (Ed.). Op. cit., e Olafson, op. cit., p. 175-188.

${ }^{22}$ Ver Nell, E. J. Review Essay (de C. G. Hempel's Aspects of Scientific Explanation). History and Theory, v. 7, n. 2, p. 224-40.

${ }^{23} \mathrm{Ibid}$., passim. Existem, naturalmente, muitos problemas gerais conectados com a indução, mas existem poucos para serem resolvidos por meio do conceito de "lei geral".

${ }^{24}$ Essas questões foram tratadas em outros trabalhos.
} 
afirmação de "Sempre que houver A então haverá B" ou "Só se houver A então haverá B", mas implica apenas que "porque" tem sempre uma referência para além do caso individual, em virtude da generalidade das descrições em que os fenômenos em questão são explicados (ATKINSON, 1978, p. 102)25. Conceitos trazem consigo consequências lógicas que podem ser consideradas (para alguns propósitos) como conjuntos de pressuposições sobre casos semelhantes. Se estamos preparados para afirmar que a URSS enviou tropas para a Tchecoslováquia, porque seu interesses vitais foram ameaçados, então devemos estar preparados para mostrar as diferenças relevantes se quisermos repudiar uma explicação semelhante em circunstâncias aparentemente similares. O pressuposto de que as grandes potências irão proteger seus interesses vitais é vago e "meramente" sugestivo, mas não um truísmo vazio ou totalmente formal, porque construído sobre o caso que implica que são sugestões a respeito de que tipo de coisa pode ser um interesse vital. Mesmo assim, se as circunstâncias são diferentes, ou os poderes diferentes, ou se eles falham em reconhecer os seus interesses, ou se eles têm razões imperiosas - a lista é indefinidamente longa - o pressuposto irá falhar ${ }^{26}$.

Sua aplicabilidade está sempre em questão, porque será uma questão de julgamento sobre o que é para contar como "o mesmo" e quais são os aspectos que são relevantes para decidir isso. Até que ponto os eventos na Polônia têm que ser analisados antes da intervenção impelida pelos "interesses vitais" da URSS? A generalidade mínima implícita no emprego de um conjunto de conceitos em vez de outros, na história, registra o julgamento de um historiador (muitas vezes singular) e indica onde ele poderia olhar sob outros pontos de vista, ao invés de significar a aplicação de uma lei formulada de forma independente ou com antecedência. Por esta razão, se optarmos por considerar essa generalidade implícita como mais do que formal, bem como considerar o fornecimento do conjunto de pressupostos para outros eventos, isto é essencial

${ }^{25}$ Um ponto similar é feito por Nell, op. cit., p. 230. A afirmação tradicional de que a história está preocupada com a compreensão de eventos particulares mais do que em subsumi-los sob as leis gerais não é, portanto, falsificada. O fato de que nós empregamos conceitos como empreendimento cognitivo (para não ser forçado) não mais comprometendo historiadores na busca ou no emprego de leis gerais do que (diriam) os críticos de arte. O objeto de comparações e contrastes além do caso citado pode ainda ser "a ampliação da própria compreensão do caso individual e não a sua assimilação pelos outros casos pela sua submissão à lei” (ATKINSON, 1978, p. 113).

${ }^{26}$ Peter Rogers argumenta que essas pressuposições são preenchidas ou completadas em história dentro "de generalizações elaboradas indutivamente", reduzindo sua formalidade ainda mais. Eu concordo que isso acontece e que nós raramente temos algo melhor para fazer, mas tendo um ponto de vista mais pessimista sobre as predições baseadas a partir deles. Uma dificuldade aqui pode ser ilustrada comparando com as concepções de Gladystone e Disraeli sobre "interesses vitais". Mas eu concordo com Peter Rogers que, enquanto instrumentos heurísticos, tais generalizações são de uma grande importância no ensino de História. 
para perceber que estamos lidando com um dispositivo heurístico, cujo papel é chamar a atenção para certos elementos em uma situação como possivelmente importante. $\mathrm{O}$ mais explícito e preciso torna-se uma lei em tais pressupostos. No entanto, não é provável que uma lei seja relevante em todas situações. Atkinson sugeriu uma analogia aqui com os canhões de gosto: "É amplamente reconhecido que tais canhões, mais que muletas para iniciantes ou material para os produtores de livros didáticos equivocados, são defensáveis apenas na medida em que nos encorajam para olhar, através deles, para obras exemplares, para os temas de comparação e contraste, que são as bases sobre as quais eles ocorrem." (ATKINSON, 1978, p. 114). Pressupostos e generalizações mínimas e implícitas, decorrentes dos conceitos empregados na explicação, raramente são encontrados como declarações explícitas no trabalho histórico, mas são geralmente tornados explícitos, a fim de deduzir um conjunto de alternativas de pressupostos. Onde eles surgem é nos livros escolares e em transcrições de fala de professores em interação em sala de aula, ou na popularização da história ${ }^{27}$. Isso é importante - "muletas para iniciantes" é um pouco de desprezo - para alguém aprender história: generalizações sugestivas são válidas e úteis, enquanto isto é realizado não como destilações de, ou resultado formal de pesquisa histórica. A questão não é aplicá-las, mas ver além delas.

Muitas destas pressuposições e generalizações implícitas vêm a ser semelhantes aos "princípios de ação" de Dray. Hence Taylor explica essa generalização, em que a suspeita é a relação normal entre grandes potências, com um princípio esquemático de ação para conselheiros militares. "Afinal, é o trabalho de generais, almirantes e marechais do ar de se preparar para as guerras. Eles só podem se preparar mesmo para a guerra, sensatamente, se preverem um antagonista, e quando eles não podem ver um antagonista óbvio, então, eles encontram antagonistas improváveis." (TAYLOR, 1978, p. 158). Da mesma forma, intimamente questionado por um aluno sobre cuidados com franceses e holandeses durante a campanha de Marlborough Blenheim, um professor responde: "Generais não travam batalhas, a menos que eles pensem que vão ganhá-las.” Tomada tal como está, essa última afirmação é simplesmente falsa. Mas, tomada como algo parecido com um princípio de ação para o período relevante, quando a formação e manutenção de tropas profissionais foi extremamente caro e a guerra estava longe de ser total, chama a atenção para o que é provável que seja uma importante premissa militar. E é usado na lição, tanto para mostrar como a maioria dos generais eram susceptíveis de se comportar como para indicar que Marlborough era diferente. Um princípio de

${ }^{27}$ Ver, por exemplo, Taylor (1979, p. 158): “[...] suspeição é o relacionamento normal entre os grandes poderes". 
ação é defensável em casos individuais, sem que isso seja considerado como inútil.

Se tão simplista distinção é permitida, pode-se dizer que a história não é uma atividade prática (mas uma atividade cognitiva) que, em situações importantes, é como atividade prática. Nela, uma massa de conhecimento é produzido e isso pode ser adquirido por qualquer um que aprenda história. Mas este conhecimento não é formalizado ou articulado em esquemas dedutíveis. $\mathrm{E}$ porque não é formalizado, não pode ser aplicado em todas as instâncias, mas somente aplicado em certos $\operatorname{casos}^{28}$. O conhecimento histórico pode ser considerado como (entre outras coisas) uma experiência vicária: ela aponta para o que pode ser esperado, enquanto que faz-se evidente que o que é esperado é, raramente, como acontece. Isto dá alguma concepção para uma gama de possibilidades e abre a oportunidade de tomar esta concepção de forma reflexiva.

A experiência histórica de um homem afeta seu senso de probabilidade, a escolha das coisas que ele acha possíveis de acontecer, porque ele acredita que já aconteceram antes, ou os motivos que ele acredita como prováveis de serem tratados, porque ele pensa que homens trataram deles antes. Em todos esses problemas, é importante que homens e mulheres percebam o que, provavelmente, influencia o seu jeito de pensar, porque é somente se fizerem isto que eles podem trazer tais influências sob um certo tipo de controle. ( KITSON CLARK, 1967, 197).

A consciência da crença de alguém é somente uma condição necessária para trazer as influências sob controle, não uma condição suficiente. E, é claro, um senso do provável não é um padrão do possível: esse tipo de experiência é desastroso se for usado para ser mecanicamente aplicado para o futuro.

A noção de experiência vicária será estudada na seção IV, mas há mais um jeito pelo qual a história pode fornecer alguma adesão do futuro, já mencionada na seção I. Mais uma vez, as concepções centrais são aquelas de intencionalidade e historicidade. Ação política, movimentos institucionais ou desenvolvimentos, manipulação ou tolerância econômica, todos os conceitos fazem referência ao que está acontecendo e são, ao mesmo tempo, relatos do que já aconteceu. Isto é particularmente claro no caso de políticas que são temporariamente prolongadas. A política do Partido Trabalhista, por exemplo, traz consigo um certo entendimento do que já foi feito por e do que aconteceu no Reino Unido no passado, e o que eles significam dentro do contexto de tal passado (OLAFSON, 1979, p. 148). O mesmo é verdade (por exemplo) na

\footnotetext{
${ }^{28}$ Referência para "casos" pode ser uma distante analogia com a prática clínica, mas ela ainda implica muito próximo aos "exemplos".
} 
política estrangeira de Hitler ou na política de apaziguamento. De forma mais generalizada, tradições de todo tipo envolvem compreensões compartilhadas e, apesar destas,

[...] podem ser representadas em forma de princípios gerais a partir dos quais uma aplicação nas circunstâncias do presente é, então, dedutivamente derivada [...] é duvidoso se essa é, de fato, a forma na qual a tradição seria entendida pelo povo em questão. A visão mais plausível é que essa tradição é mantida na mais particularizada e concreta forma de uma conta do que a sociedade fez e sofreu, por um período de sua existência. (OLAFSON, 1979, p. 148).

Enquanto ação futura e uma continuação das normas (ou tradição), o conhecimento histórico pode fornecer visões para o futuro, por meio de sugestões de que movimentos possam contar como parte daquela norma. Isso não ratifica o relato do passado encravado em tais normas ou tradições, mas cria a possibilidade de compreensão e avaliação delas.

Além disto, dado que qualquer ação é concebida dentro de um certo contexto e de um certo jeito, o conhecimento de elementos históricos (referências do passado), nesta situação, ajudará em qualquer análise do que é possível ser feito. Taylor, por exemplo, chamando a atenção de uma audiência leiga para partes do passado que ele claramente pensa que ela sabe pouco, declara:

De fato, a Rússia foi invadida por um país europeu, ou outras cinco vezes, desde o início do século dezenove. Por Napoleão em 1812, pelos britânicos e franceses em 1856, pelos alemães em 1914 até 1917, pelos britânicos e franceses de novo em 1919 e pelos alemães em 1941. A Rússia nunca invadiu a Europa, exceto em resposta ao conquistador e pode-se dizer, como libertador (TAYLOR, 1979, p. 170).

É claro que se a asserção de Taylor fosse aceita ela levaria a certas expectativas do comportamento soviético no futuro diferentes daquelas que seguem uma análise mais céptica da história soviética. Isso não é porque estamos autorizados a esperar que a URSS fará sempre o que fez no passado, mas porque nossa compreensão de como aqueles que controlam as políticas soviéticas podem ver as coisas foi modificada. A questão é que, para entender o que a URSS fez em uma determinada época e ter uma melhor ideia do que ela poderia ter feito na sequência, é necessário saber a história. Além disto, o conhecimento histórico pode excluir certas concepções do passado e então mudar nossas concepções do futuro - do que é possível e desejável ${ }^{29}$. O controle da história

${ }^{29}$ Essa investigação demandaria algumas concepções do passado irlandês sustentado por participantes no conflito da Irlanda e, portanto, algumas concepções sobre a ação possível, e isso não 
sobre o futuro não está confinado a avaliações de probabilidades do que pode acontecer a nós (ou apesar de nós), mas nos oferece alguma base sobre a qual podemos decidir como agir. E, é claro, já que o que é tentado é raramente o que é alcançado, o conhecimento histórico pode (com o tipo de qualificação levantada através dessa seção) indicar onde olhar para ver o que pode ter uma relação entre os eventos, independentemente do que quaisquer agentes históricos pensem que eles estão fazendo.

A História diz respeito ao estudo do passado e não do futuro. Mas algum conhecimento sobre o passado nos dá um alcance (mesmo que ligeiro) sobre o futuro. Esse alcance não é fortalecido pela tentativa de fazer da história uma fonte pseudocientífica de predições: ela somente tem alguma coisa distinta a oferecer quando nos reportamos a ela ${ }^{30}$. Não está sendo defendido aqui que historiadores e aqueles que estudaram história serão melhores copistas do futuro do que os não historiadores, porque muitas coisas, além do conhecimento histórico, entram nessa questão. O que está sendo colocado é que um homem com um conhecimento da história estará melhor situado não mais do que um homem carente desse conhecimento, mas do que ele próprio estaria se não tivesse esse conhecimento.

\section{Experiência vicária}

A História possibilita uma experiência vicária. Mas, o que se quer dizer com isso? Experiência é usada para indicar alguma coisa pessoal (mas não meramente subjetiva) e alguma coisa acumulada como que se torna mais ex-

significa fornecer pessoas com notícias, pois informações mais acuradas os reteriam, sustentando suas visões. As pessoas podem ter outras razões para sustentar seus pontos de vista. Se nós substituíssemos o conhecimento e a compreensão do passado, então ex hypothesis os pontos de vista mudariam. Mas, isso é meramente um ponto conceitual, e, é claro, muito frágil para afetar questões substantivas: a) se isso é possível nas circunstâncias econômicas presentes; b) como ele poderia ser alcançado.

${ }^{30}$ Existe um perigo aqui em dizer "história fornece uma habilidade para fazer A, B e C. Então, em vez de se preocupar com trabalhar com fatos dados, ou pensando muito sobre o passado num modo substantivo, vamos ensinar A, B e C". Se isso era simplesmente uma preocupação contra sustentar informações estéreis - porque não existe compreensão - ela seria suficientemente inocente. Mas, ela pode levar a confusões em relação ao que existe em história para ser ensinado. Isso é, talvez, evidente em CONNEL-SMITH, G.; LLOYD, H. A. The relevance of history. Portsmouth: Heinemann Educational Books, 1972, no qual, "um conhecimento exato dos eventos passados" é contrastado desfavoravelmente com, por exemplo, "hábitos de julgamento e capacidade para ação" (p. 28), e uma abordagem advogada que eleva as necessidades das pessoas vivas sobre obrigações teóricas em relação "ao passado" e à "posteridade" - ou mesmo para aqueles conceitos mais importantes, "verdade objetiva" (p. 85). É simplesmente assumido que "um conhecimento exato dos eventos passados" pode não ter conexão com "hábitos de julgamento e capacidade para ação" e que "obrigações teóricas sobre o passado" podem não ter significado para as "necessidades práticas da vida". Quem presumivelmente não tem necessidade da verdade objetiva para os seus propósitos mundanos e cotidianos! 
perienciada. $\mathrm{O}$ que é adquirido não é necessariamente codificável e não dará a fórmula nem a receita para a ação. Há paralelos aqui com a arte e o ofício ou com a prática de habilidades complexas ${ }^{31}$. Alguém que tem experiência no significado em questão pode ter dificuldade para articular com princípios gerais, ou, se ele puder, sentirá que eles não são aplicáveis sem a experiência de qualquer um que procure segui-los. Um professor experiente é capaz de ver coisas que um sem experiência iria perder e saberá com que tipo de situação terá de lidar. Um homem do mar pode saber que clima será favorável sem ser capaz de explicar como o sabe. Não há nada misterioso aqui. Muitas coisas são envolvidas: ter as concepções corretas, reconhecer exemplos, saber princípios, reconhecer condições sob as quais eles são aplicáveis, ser capaz de identificar tendências contrárias e assim por diante. Com tempo, prática e experiência, paciência, e um leque de experiências, a maioria das pessoas pode aprender o que é requerido. Mas sem experiência, mesmo se os princípios gerais fossem considerados e isto poderia ser feito de um jeito formal, eles seriam de pouco uso. Eles não poderiam ser mecanicamente aplicados.

A experiência adquirida pela história é vicária: de maneira óbvia, é de segunda mão. Pessoas que leem sobre (ou mesmo pesquisam) modos diferentes de vida não os vivem por causa disto e seguir o caminho de negociações diplomáticas não significa estar engajado na diplomacia. Mas, procurando entender por que as pessoas fizeram como fizeram e por que a diplomacia procedeu de tal forma, uma pessoa pode expandir o leque de situações com que está equipado para reconhecer e o leque de possibilidades que está preparado para encontrar.

Falando de reconhecer situações, a própria preparação pode parecer otimista em vista do que foi dito na seção III. Mas, de novo, não é uma questão de seguir uma receita ou aplicar uma fórmula. É conseguir conhecer indivíduos históricos (sociedades, nações, partidos políticos, instituições) que ainda estão conosco e têm tradições e normas com tipos de referências lá de trás. Isso significa a compreensão do sistema de valores e crenças e as condições materiais em que são baseados ${ }^{32}$. É sabendo algo da imensa variedade de jeitos que pessoas tiveram e como as sociedades foram ordenadas (colocadas em ordem) que é possível agir. E isto é reconhecer a importância das contingências - acidentes, coincidências ou outros imprevisíveis acontecimentos - em todas as aventuras (empreendimentos) humanas, relacionamentos e instituições (GALLIE,

\footnotetext{
${ }^{31} \mathrm{Nada}$ disso tem significado para se recusar a existência de princípios ou mesmo regras operacionais na estética.

${ }^{32} \mathrm{Eu}$ não tentarei clarificar como eles podem ser sustentados: isso é uma tarefa além de minha competência.
} 
1964, p. 133) $)^{33}$. Tal experiência vicária é útil somente em negócios práticos, ela abre novos modos de ver coisas (e assim por diante, sob uma remoção, novas possibilidades de ação) mais do que receitar o que pode ser feito.

Experiência deste gênero será de nenhum valor sem um tipo de mente aberta, que a história por si só não pode garantir, mas que é construída em um estudo histórico. Ao mesmo tempo em que um conhecimento histórico requer a articulação das razões e a habilidade de ver coisas de um ponto de vista diferente, ele pressupõe que as pessoas tenham razões para fazer coisas, exigindo um princípio mínimo de racionalidade (como oposto, para racionalidade, é a irracionalidade). É através disto que algo pode ser salvo, a partir da afirmação desacreditada que aprender história desenvolve a tolerância. A tolerância oferecida pela história não é uma vaga sensação de simpatia ou perdão, que aceita tudo sobre a base de bom senso humano e relativismo generalizado. É apresentar vontade e habilidade para entrelaçar crenças e valores que não são necessariamente aceitos (muito menos compartilhados) com o propósito de entendimento $^{34}$. Mas entender não é aceitar ou até manter criticismo sobre a eficiência dos meios ou do valor dos fins. Uma tolerância histórica genuína deve ser bem informada e crítica. No entanto, mais do que isso não deve ser afirmado aqui. Nós não sabemos realmente o que afeta modos específicos de ensinar história, nem sabemos o que exatamente tem de ser ensinado para que uma compreensão e tolerância histórica desse gênero possam ser alcançadas ${ }^{35}$. Potencialmente, de qualquer modo, a experiência vicária a ser encontrada no ensino de história é libertária. Ela pode expandir nossa concepção do que o "homem" é capaz, mostrando-nos o que ele fez, pensou e foi, e como ele mudou. Mais diretamente, supre uma imensa gama de exemplificações concretas de ideais individuais, manifestações do modo de vida que é possível se levar. Pessoas podem assumir diferentes modos de vida (ativa, contemplativa, prática etc.), objetivos diferentes

${ }^{33}$ Gallie argumenta que a história "pode e deve ajudar-nos a alcançar a "poderosa manipulação da previsão". Ele admite que seria um paradoxo absurdo esperar que a história nos ajude a antecipar ou prever "desenvolvimentos especialmente preditos", mas argumenta que ela pode, de uma maneira análoga à prática de jogos de habilidade, preparar "para qualquer coisa que acontecer". Ele desenvolve a analogia em termos de "forma" - "uma prontidão, rapidez e flexibilidade de respostas" - e formula dois quase princípios, cuja função é cobrir aquelas situações que escapam da rede de nossos outros princípios e categorias. Essas ele chama de "princípios de reserva" e "os princípios do tudo ou nada". Parece-me que Gallie isolou algo importante para assuntos práticos, o que levanta a necessidade de muitas futuras análises. É verdade que "forma" em jogos não é simplesmente uma matéria física, mas a analogia tem escopo limitado, porque a experiência em história permanece vicária - é no sentido da experiência do "expectador".

${ }^{34}$ Ver LEE, P. J. Explanation and understanding in history. In: DICKINSON, A. K.; LEE, P. J. (Eds.). History Teaching and Historical Understanding. Portsmouth: Heinemann Educational Books, 1978.

${ }^{35}$ Ver os trabalhos de Peter Roger. 
(poder, aprendizagens, riqueza etc.), papéis diferentes (cientista, soldado etc.) e diferentes estilos de vida ("responsável”, iconoclástico, artístico etc.). Desde que faça sentido falar de pessoas fazendo escolhas, a história supre alguma base concreta sobre a qual as decisões são tomadas. Também dá pistas das possibilidades que não são encontradas exemplificadas no mundo contemporâneo, sobre as quais nenhuma atenção é dada, ou as consequências que ainda não foram compreendidas nos termos atuais. Obviamente, isso é de particular significado para as crianças, a quem são constantemente oferecidos ideais individuais demandados por interesses comerciais de uma sociedade industrial capitalista e por um espectro relativamente estreito de opinião política ${ }^{36}$.

Devido a todos esses aspectos da experiência vicária, a imaginação pode ser considerada central, como um ingrediente e também como algo que é para ser desenvolvido. No sentido de estabelecer cenários diferentes para a investigação e a imaginação de possibilidades, a história encoraja e exige a imaginação de duas amplas formas. Exige imaginação de dois modos de vida e diferentes crenças e valores como parte da compreensão histórica. Esse é um aspecto fundamental da imaginação histórica, do qual é passível presumir ${ }^{37}$. Ao mesmo tempo, no sentido de obter avaliações de importância ou de localizar causas como condições necessárias, a história encoraja a imaginação de ações alternativas, eventos, resultados. Aqui os eventos imaginados são imaginários, mas não são produtos incontroláveis da fantasia ${ }^{38}$.

A experiência vicária, que é adquirida no ensino de história, estimula a imaginação e expande a concepção do educando do que é ser humano e, assim, do que ele ou ela é ou pode vir a ser. Nisso, como em tudo discutido nesse capítulo, a afirmação é que uma pessoa que aprendeu alguma história (incluindo aqui tanto o conhecimento substantivo como o de segunda ordem) estará melhor equipada para lidar com o mundo do que ela estaria se não tivesse aprendido. Isso não significa afirmar que alguém que estudou história será, ipso facto, melhor político, empresário, cidadão ou professor do que alguém que não estudou.

Ser modesto, contudo, pode oferecer algumas vantagens. O tempo para educação é limitado (e não somente nas escolas). Alguma história pode ser melhor que nenhuma - mas, como pode a história competir, em termos de tempo, com outras disciplinas? Além do mais, a história não é tão útil quanto a Ciência

\footnotetext{
${ }^{36} \mathrm{Eu}$ não defendo, é claro, o ensino de história por meio de biografias, com uma série de lições morais para ser aprendida a partir da vida dos "grandes homens".

${ }^{37}$ Já desenvolvi essas ideias em outros trabalhos.

${ }^{38}$ Mesmo se alguém der valor às declarações de alguns historiadores para o fato de que eles não estão interessados no que poderia ter acontecido e, portanto, concluído, isso não é estritamente histórico, a imaginação pode ter importante lugar na aprendizagem histórica.
} 
ou a Matemática. A fraqueza dessa objeção está na sua concepção crua sobre o que é útil. $\mathrm{O}$ útil é frequentemente colocado contra o intrinsecamente válido e há algum sentido em tal justaposição. Mas alguma coisa que expande a nossa própria concepção de mundo não entra também dentro dessa categoria. Ao mesmo tempo, seria estranho afirmar que tudo o que tenha produzido uma expansão é inútil, mesmo não sendo aplicável num objetivo específico sobre um modelo da tecnologia. É sempre esquecido que as maiores realizações da ciência têm sido do tipo não tecnológica. Atividades como estas são valiosas, seja intrinsecamente, seja para atingir um fim. Naturalmente, alguma coisa útil (enquanto instrumento) num sentido estrito pode adaptar-se a muitas finalidades e, então, existe, frequentemente, ampla concordância que ela é útil (mesmo entre pessoas com objetivos conflitantes). Por outro lado, existem grandes diferenças quanto às finalidades e então é difícil obter acordos acerca do que é importante num sentido não tecnológico. Mas, afinal, devem existir algumas coisas importantes, ou nada poderia ser útil como instrumento. O tema desse artigo é ter argumentado que a história é valiosa justamente nesse sentido não tecnológico.

\section{REFERÊNCIAS}

ATKINSON, R. F. Knowledge and explanation in history. New York: Macmillan, 1978.

DAVIDSON, D. Action, reasons and causes. In: WHITE, A. R. (Ed.). The philosophy of action. Oxford: Oxford University Press, 1968.

GALLIE, W. B. Philosophy and Historical Understanding. London: Chatto \& Windus, 1964.

KITSON CLARK, G. The Critical Historian. Portsmouth: Heinemann Educational Books, 1967.

OAKESHOTT, M. Experience and Its Modes. Cambridge: Cambridge University Press, 1933.

OAKESHOTT, M. The activity of being an Historian. In: . Rationalism and Politics. London: Methuen, 1962.

OLAFSON, F.A. The dialectic of Action. Chicago: University of Chicago Press, 1979. 
PLUMB, J. H., The Death of the Past. New York: Macmillan, 1969.

TAYLOR, A. J. P. How Wars Begin. London: Book Club Associates, 1979.

Recebido em 11 de abril de 2011.

Aprovado em 30 de junho de 2011. 